\title{
THE POSSIBILITIES OF DYNAMIC SHIPMENT WEIGHING IN RAIL FREIGHT TRANSPORT
}

This article deals with an analysis of the methods of the dynamic weighing of rail vehicles. The measurement of axle load (both static and dynamic) is one of the current standard processes within the technical specifications for interoperability (TSI).

Keywords: Rail transport, vehicle weighing, interoperability.

\section{Introduction}

The weighing of posted shipments is important in all spheres of transport. Overloaded freight vehicles represent a serious danger for transport in the form of higher risks for other traffic participants and lower traffic safety. The issue also has significant impacts on the life expectancy of infrastructure and can lead to unfair competition between various modes of transport and their providers.

In most cases the sender is the one who specifies the weight of the goods. It is for this reason that a forwarder has the right to verify the specified weight anywhere and at any time. However, there is a problem with the availability of rail scales. This is why the number of overloaded modes of transport must be minimized. The introduction of in-motion weighing has big potential. New technologies have led to the development of a complex, fully equipped and reliable system for the dynamic weighing of rail vehicles i.e. in-motion weighing. Such systems are certified as so called rated gauges. The results of the checked weight are compared to the real weight and the permissible weight for a given means of transport infrastructure. Sanctions are then imposed on those vehicles exceeding the permissible weight [1].

\section{Dynamic Weighing method}

The current method of weight detection is similar to that for tolls in road transport. It is based on the detection of operational load and the number of passing rail vehicles. This may also include, as the case may be, the dynamic effect of the operation on the railway infrastructure in terms of the effects of wear on measurement and on the consequent processing and evaluation of the measured data for the purposes of tolling. This method requires - like for road tolls - the installation of measurement points at individual track sections which are part of a paid railway infrastructure. The measurement points consist of measurement equipment which can either operate on the principle of dynamic weighing or on the detection of the dynamic impacts of passing rail vehicles. This system has the advantage that it records the whole load as it passes through the installed measurement point [2].

The efforts to introduce the dynamic detection of the weight of shipments in rail freight transport relates to the efforts to ensure the so called interoperability of the European railway transport system. The interoperability of railway systems is the basic precondition for the functioning of the integrated transEuropean conventional railway system. The term interoperability involves the ability to provide mutual support for various facilities, operational and technical links for safe and uninterrupted movements, and the provision of the basic operational and technical conditions on the selected network of railways for the safe and uninterrupted operation of rail vehicles [3].

To achieve these goals some measures have been taken, particularly in the field of technical standardisation, which resulted in the technical specifications for interoperability (TSI). The issue of the measurement of static wheel load is one of

\footnotetext{
* 1 Jan Lizbetin, ${ }^{2}$ Petr Vejs, ${ }^{3}$ Zdenek Caha, ${ }^{4}$ Lenka Lizbetinova, ${ }^{5}$ Philip Michalk

${ }^{1}$ The Institute of Technology and Businesses in Ceske Budejovice, Faculty of Technology, Department of Transport and Logistics, Czech Republic ${ }^{2}$ University of Pardubice, Jan Perner Transport Faculty, Czech Republic

${ }^{3}$ The Institute of Technology and Businesses in Ceske Budejovice, Faculty of Corporate Strategy, Department of Foreign Languages, Czech Republic

${ }^{4}$ The Institute of Technology and Businesses in Ceske Budejovice, Faculty of Corporate Strategy, Department of Tourism and Marketing,

Czech Republic

${ }^{5}$ Technische Hochschule Wildau (FH) Hochschulring 1, 15745 Wildau, Germany

E-mail: lizbetin@mail.vstecb.cz
} 
the standardisation processes in progress. The project team is currently drawing up a draft of this standard.

TSI limits the static axle load for interoperable rail vehicles to 17 and 19 tonnes for high speeds of $200-250 \mathrm{~km} / \mathrm{h}$ and over 250 $\mathrm{km} / \mathrm{h}$ respectively. These maximum values provide a tolerance of $2 \%$ on the average axle load of a complete train. A tolerance of $4 \%$ per individual axle is acceptable. In addition, the difference between the right and the left side of one vehicle must not exceed $6 \%$. These values are considered achievable for the Rail WIM (weight-in-motion) system to measure. Some selected WIM measurement systems are briefly characterized in the following part of this article [4].

\section{Footprint measurement station (NED-Train, Netherlands)}

The measurement system consists of four sensors, an electronic recording unit and a central server (Fig. 1). The whole measurement system is based on the sensor unit, which is installed on the rail foot by means of special fixtures. The measurement principle is based on glass fibre technology and the change in their properties under load. The light guide technology has the advantages that it is quick to install and dismantle, demands little maintenance and operates independently of influences caused by electromagnetic fields [4].

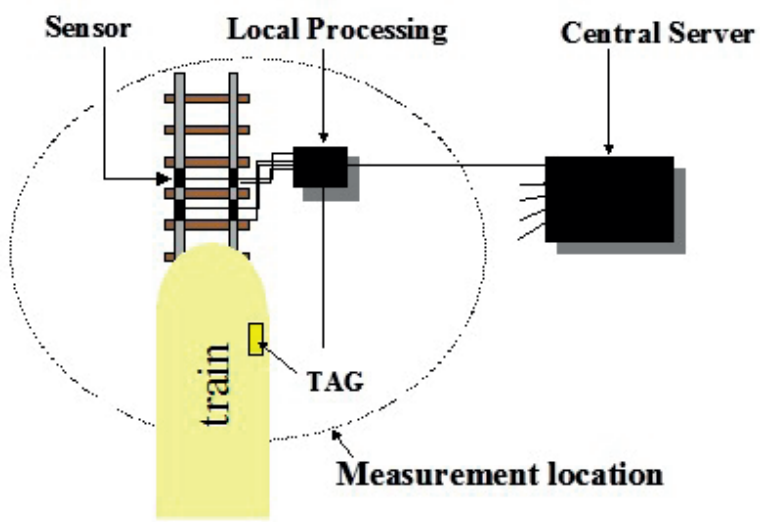

Fig. 1 Schematic illustration of the measurement system; source: [4]

The sensor consists of optical fibres and is attached to the bottom of the rail foot, where it measures the deflection of the rail at the moment of wheel passage. The signal generated by the wheel passage is shown in Fig. 2.

The axle passage is on the horizontal axis and the degree of deflection on the vertical axis. The passage of a defective axle not only causes the rail to deflect, but also to vibrate. Four sensors installed at exactly defined distances provide sufficiently reliable information about the wheel defect.
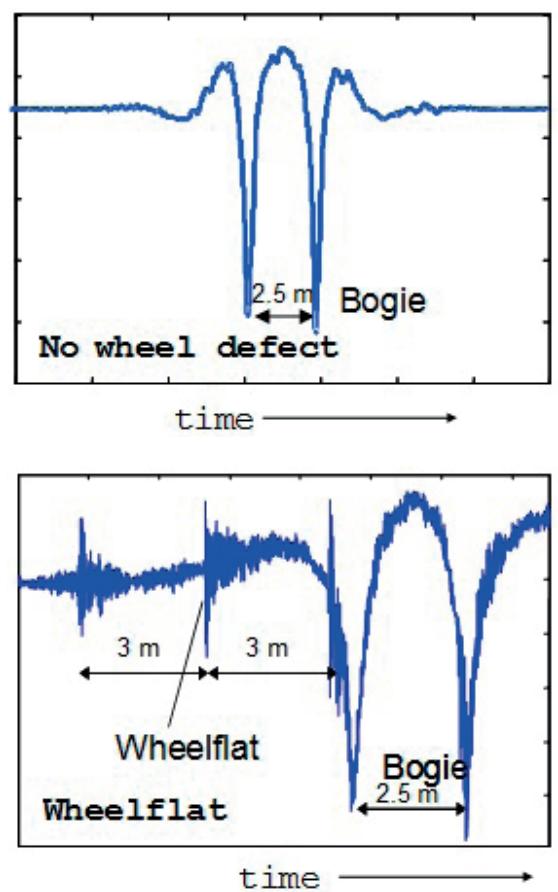

Fig. 2 The output signal of the sensor provides information on wheel quality: without a defect (left), with a defect (right); source: [4]

The whole system was tested up to a maximum speed of $160 \mathrm{~km} / \mathrm{h}$. Theoretical and laboratory tests have proved that the sensors are able to measure weights and detect load at up to at least $300 \mathrm{~km} / \mathrm{h}$. The passage speed of the individual axles can also be measured with high accuracy because two sensors are always installed on each rail. The sensors generate data, which after being processed by the local processor unit, provides information on axle load, wheel load, wheel quality, speed and the number of axles. The types of the individual wagons can also be detected and the symmetry of the load distribution on the individual wagons assessed [5 and 6].

\section{Rail WIM measurement station (KISTLER, Switzerland)}

The Rail WIM Kistler 9000M071 system is able to detect the weight, overload and asymmetric load of rail vehicles. The system detects the vertical load (force) on the individual wheels, axles and wagons in motion by means of a digital processor located in an electronic box. The partial load on the front and rear axles and the left-right load are also analysed to detect the asymmetric load on each rail vehicle. The addition of the individual axles and wagons is automatically performed by means of evaluation software. The total weight of the whole train is determined as the sum of the individual weights. The Automatic Equipment Identification (AEI) reader captures the identification numbers of the rail vehicle, which are held as part of the stored data [7]. 
Rail WIM is designed for installation on main routes, where it is able to detect, record and evaluate the load data of all the passing trains. The permitted train speed is from 5 to $60 \mathrm{~km} / \mathrm{h}$ in both directions. Slower trains or those that stop at the place of measurement cannot be measured by this system. In such cases a system error occurs. The higher speed limit is limited in principle by the detection capability of the AEI antenna. The sensors themselves and the signal processing system are able to measure the weight of passing trains at speeds higher than $80 \mathrm{mph}$ (approx. $130 \mathrm{~km} / \mathrm{h}$ ).

Rail WIM is designed for the measurement of individual rail wagons with an accuracy of $2 \%$ with a confidence interval of $95 \%$. The $95 \%$ reliability level is defined as 2-sigma random error of measurement, which is the error without the calibration error. The calibration error can be arbitrarily small. It is adjustable by means of the system software, and depends on the accuracy of the "known" weights of rail wagons and locomotives [8].

Figure 3 shows a typical Rail WIM measuring station installed on a main railway. Detailed installation instructions are in the company user manual. The distances between the individual sensors have been shortened for the sake of the clarity of the illustration [8].

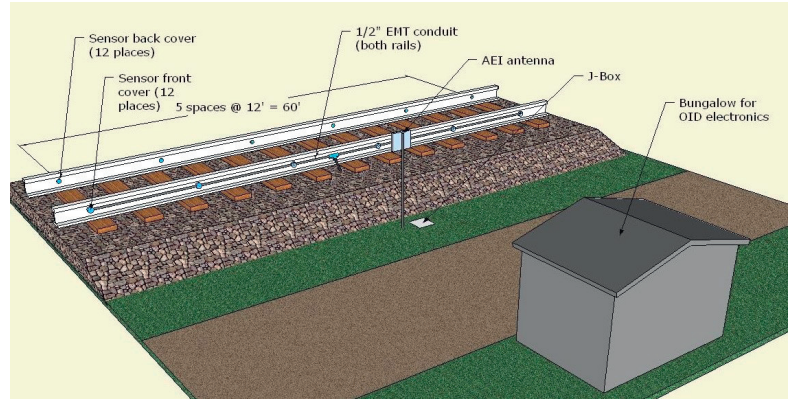

Fig. 3 Configuration of the Rail WIM Kistler station; source: [8]

\section{Dynamic and static scales for rail vehicles (Buchmann, Germany)}

\section{"EcoRail" type}

The device is used for the detection of rail wagon overloading. The weighing range is up to 120 tonnes with a scale segment of $50 \mathrm{~kg}$ and axle weight of up to 30 tonnes.

Weighing without a certificate is performed within the speed range from 8 to $10 \mathrm{~km} / \mathrm{h}$ (vehicle passage speed). The measurement accuracy lies between $1.0 \%$ and $2.0 \%$, depending on the railway body and the quality of the superstructure. The installation of the device is very simple. Eight sensors are pressed into pre-drilled holes in the rails. The sensors are installed in the rail sections between sleepers (Fig. 4). No special foundations or any alterations to the railway superstructure are required [9].

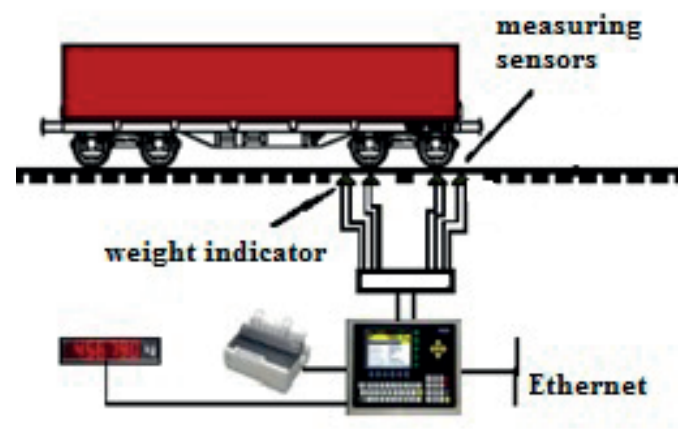

Fig. 4 Scheme of the Ecorail system; source: [9]

\section{"EcoDywa" type}

"EcoDywa" dynamic railway scales are certified according to the international metrological regulation OIML R106. The scale's structure consists of steel bridge scales installed on a flat foundation of reinforced steel. The scales are designed for the dynamic measurement of the axle weight and total weight of rail wagons, including identification of wagon type. The scales are calibrated for the dynamic and static weighing of rail vehicles (including tank wagons) used for the transport of liquids, with loosely loaded goods and piece transport [9].

\section{"Lars-M" portable static and dynamic railway scales}

This is a system designed for quick measurements, e.g. wagon overloading (Fig. 5). The scales are suitable for rail gauge $1435 \mathrm{~mm}$ and various types of other rails S49, S54, UIC60, etc. The weighing is performed at speeds of up to $5 \mathrm{~km} / \mathrm{h}$ [10].
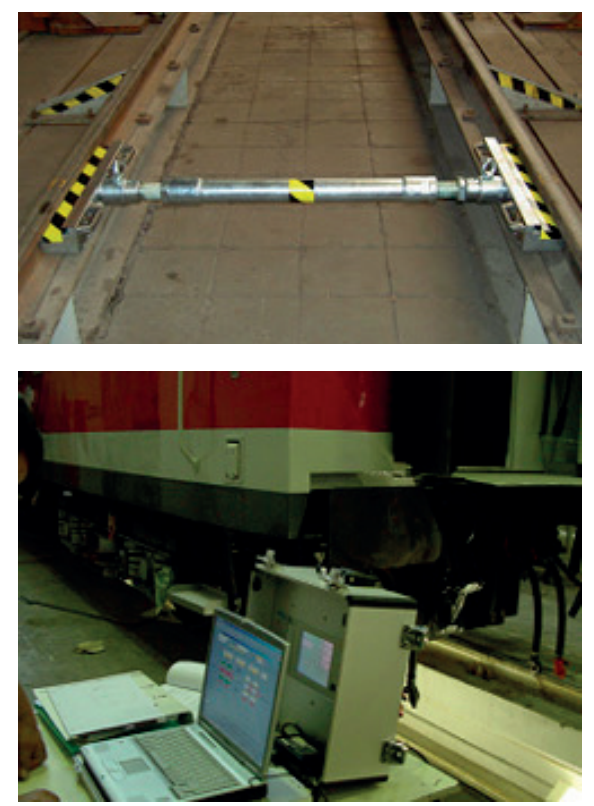

Fig. 5 Scheme and example of the Lars M system; source: [10] 


\section{Rail WIM (Israel)}

The system is based on the principle of piezoelectric ceramic sensors, which are glued to a rail foot. The sensors are installed on various parts of the rail: on top of the rail foot, on the bottom of the rail foot and on the web of the rail. There are 20 sensors in total, installed equidistantly according to the wheel perimeter. The system measures forces (deflection) and can also detect defects on the individual wheels by means of an analysis of the signals. The measurement accuracy oscillates between $0.5 \%$ and $1 \%$ in comparison with static weight. The system measures wheel loads, axle loads and the total weight of rail vehicles. Auto-calibration of the Rail WIM system is performed by means of a "batch" unit (RFID), which is attached to an engine [11].

\section{Conclusion}

The practical significance of the detection of shipment weight, whether by means of a static or a progressive dynamic system, is particularly in the correct calculation of the price of use of the railway infrastructure. Errors in the weight of rail vehicles can result in the operator of the railway infrastructure loosing income from the charges for the use of the infrastructure. This income is important because it is compensation for the use of the infrastructure by forwarders and covers the operators costs related to the servicing of the railways and the organization of rail transport. For example, in 2013, the revenue of $\mathrm{SZDC}^{1}$ was approximately CZK 4.2 billion. This means that the "average prices" per train-kilometre and per 1,000 gross tonne-kilometres are more expensive, which corresponds to the higher proportion of $\mathrm{E}$ category tracks in operation with higher charges TERFN ${ }^{2}$ ) [12].

If we calculate with an "average" price of CZK 40 per 1 train-kilometre and with the "average" price CZK 50 per 1,000 gross tonne-kilometres we get approximately CZK 1.5 billion for the operation of the railway infrastructure (train-kilometres) plus CZK 1.7 billion for ensuring the operability of the railway infrastructure (1,000 gross tonne-kilometres) i.e. total revenues of more than CZK 3.2 billion.

The above calculation is only indicative. It is based on just one rate per 1,000 gross tonne-kilometres. In fact tracks of different categories vary not only in the charge per 1,000 gross tonnekilometres, but also with the characteristics of the operation (e.g. shorter transport distance, lower average weight of a train).

Damage to the transport infrastructure and rail vehicles as well as operational safety are some of the additional negative impacts of incorrectly specified vehicle weights [13].

\footnotetext{
${ }^{1}$ Sprava zeleznicni dopravni cesty - the operator (manager) of the railway infrastructure in the Czech Republic, which was established on the basis of the Act on the Transformation of Czech Railways, state organization (Act No 77/2002 on Czech Railways, joint-stock company and Sprava zeleznicni dopravni cesty, state organisation).

${ }^{2}$ TERFN - Trans-European Rail Freight Network, see Ministry of Transport Notification 111/2004, dated 25 February 2004, on the list of railways included in the European Railway System.
}

\section{References}

[1] CERNA, L., ZITRICKY, V., MATEJKO, P.: Price Calculation in the International Railway Transport of Goods. Logi - Scientific J. on Transport and Logistics, vol. 4, No. 2, 2013, pp. 11-27, ISSN 1804-3216.

[2] BRUMERCIK, F., KRZYWONOS, L.: Integrated Transportation System Simulation. Logi - Scientific J. on Transport and Logistics, vol. 4, No. 2, 2013, pp. 5-10, ISSN 1804-3216.

[3] FILOGRANO, M. L., CORREDERA, P., RODRIGUEZ-PlAZA, M., ANDRES-ALGUACIL, A., GONZALEZ-HERRAEZ, M.: Wheel Flat Detection in High-Speed Railway Systems using Fiber Bragg Gratings. IEEE Sensors J., vol. 13, No. 12, 2013, pp. 48084816, ISSN 1530-437X

[4] DOUPAL, E.: Measuring Technology Rail WIM, Brno : Transport Research Centre, 2012.

[5] ZHENG, C., CHEN, J.: Design of the Data Acquisition System for Mine's Dynamic Rail Track Scale, Applied Mechanics and Materials, vol. 220-223, pp. 2040-2043, 2012, ISSN:1660-9336.

[6] RINDI, A., PUGI L., MELI, E.: Weighing in Motion of Railway Vehicles: Development and Comparison of Different Identification/ Measurement Techniques. ECCOMAS 2012 - European Congress on Computational Methods in Applied Sciences and Engineering, e-Book Full Papers, pp. 1337-1356, 2012, ISBN 978-395035370-9

[7] DOUPAL, E.: Research Report PRODUCT DEFINITION, for a Railroad Freight Car Overload / Imbalance Detector (OID). Kistler Part Number: 9000M071, Kistler Instrument Corp. 75 John Glenn Drive : Certified Quality System: Amherst, NY 14228-2171.

[8] DOUPAL, E., BARZ, D.: Fusibility Study for On-line Wheel Weighing System for Rail Vehicles, Report 4-212 REV 0, Kistler AG Winterthur, 2009.

[9] TOMASIKOVA, M., BRUMERCIK, F., NIEOCZYM, A.: Vehicle Simulation Model Criterion, Logi - Scientific J. on Transport and Logistics, vol. 6, No. 1, 2015., pp. 130-135, ISSN 1804-3216. 
[10] ROZIC, T., FIOLIC, M., BACURA, M.: The Logistics Concept of Optimized Retro-Reflection Dynamic Test of Road Markings on the Roads in the Republic of Croatia. Logi - Scientific J. on Transport and Logistics, vol. 3, No. 2, 2012, pp. 128-135, ISSN 1804-3216.

[11] ZHENG, C., CHEN, J., CHEN, J.: A Mine's Dynamic Rail Track Scale with Automatic Motion Direction Judge. BMEI 2011, Proc. of 2011 Intern. Conference on Business Management and Electronic Information, vol. 1, 2011, pp. 686-689, ISBN 978-161284106-9.

[12] SUlGAN, M., SOSEDOVA, J.: Procurement of Materials and Components for Manufacturing Activity. Communications Scientific Letters of the University of Zilina, No. 2, 2014, pp. 58-62, ISSN 1335-4205.

[13] STOPKA, O., KAMPF, R., KOLAR, J., KUBASAKOVA, I., SAVAGE, C.: Draft Guidelines for the Allocation of Public Logistics Centres of International Importance, Communications - Scientific Letters of the University of Zilina, vol. 16, No. 2, 2014, pp. 14-19, ISSN 1335-4205. 